\title{
Importancia de las imágenes y el diagnóstico etiológico en el paciente inmunocomprometido con afección del sistema nervioso central. Segunda parte
}

\author{
Marcela Zubieta A., Marcela Ferrés G. y Teresa Bidart H.
}

\section{Importance of images and etiological diagnosis in the immunocompromised patient with central nervous system envolvement. Part II}

We present the case of a 12-year-old boy with acute lymphocytic leukemia who developed pneumonia and multiple brain infarcts compatible with acute necrotic encephalitis. The infectious disease screening tests revealed influenza A H1N1 virus, Staphylococcus aureus in broncho alveolar lavage, E. coli and galactomannan antigen in blood. CNS influenza associated complications are reviewed. This case highlights the importance of magnetic resonance imaging as a diagnostic tool in the assessment of immunocompromised patients with CNS compromise and the value of brain biopsy in the final identification of an infectious disease etiology.

Key words: Immunocompromised patients, central nervous system, influenza A H1N1 virus.

Palabras clave: Pacientes inmunocomprometidos, sistema nervioso central, virus influenza A H1N1.

\section{Caso clínico}

$\mathrm{V}$ arón de 12 años, portador de leucemia linfocítica aguda de riesgo medio, diagnosticada ocho meses antes del ingreso.

Dos semanas previas al comienzo de sus síntomas, estando en remisión completa, recibió un ciclo de quimioterapia con dexametasona, vincristina, doxorubicina, y L-asparraginasa. Consultó por tos y expectoración mucosa, afebril, a lo que se agregó dolor y paresia de las extremidades inferiores. Al examen físico de ingreso se encontraba comprometido de conciencia, en insuficiencia respiratoria y con signos de colapso circulatorio. La radiografía de tórax reveló imágenes de consolidación bilaterales.

Ingresó a la unidad de cuidados intensivos con los diagnósticos de shock séptico, bronconeumonía y neutropenia febril de alto riesgo. Requirió de ventilación mecánica, y aminas vasoactivas. El esquema antimicrobiano inicial incluyó vancomicina, ceftazidima, amikacina, azitromicina, aciclovir y oseltamivir; esto último por la situación epidemiológica de pandemia de influenza A H1N1. Los hemocultivos de ingreso fueron positivos para Escherichia coli.

La búsqueda de virus respiratorio sincicial, adenovirus, virus parainfluenza y virus influenza por inmunofluorescencia resultó negativa; sin embargo, resultó positiva la reacción de polimerasa en cadena (RPC) para virus influenza A H1N1 en una muestra de secreción respiratoria.
El análisis del LCR mostró un leve aumento de las proteínas y tanto la RPC para virus herpes simplex 1 y 2, como para virus influenza A H1N1 fueron negativas.

Evolución: El paciente presentó convulsiones tónico clónicas aisladas y un electroencefalograma con actividad epileptiforme frontal y témporo-parietal derecha de voltajes bajos.

En la tomografía computarizada de cerebro (TAC) se observaron múltiples lesiones hipodensas circulares, córtico subcorticales, supra e infratentoriales, compatibles con una encefalomielitis aguda diseminada.

La TAC de tórax mostró múltiples áreas de consolidación pulmonar bilateral, con predominio en el lóbulo inferior izquierdo, y opacidades intersticiales confluentes en el lóbulo medio derecho y en ambos lóbulos superiores.

Al quinto día se le realizó angioresonancia de cerebro que mostró infartos cerebrales múltiples compatibles con encefalitis necrosante aguda (Figura 1).

El cultivo de lavado broncoalveolar resultó positivo para Staphylococcus aureus meticilina sensible, incontables colonias, mientras que la determinación de galactomanano de Aspergillus spp resultó positiva con un índice de 10,3.

Pregunta: ¿Cuál cree Ud. que es la etiología del compromiso del SNC?

Respuesta: Por las características de las imágenes cerebrales, y en el contexto de una enfermedad viral como influenza, es posible plantear una encefalitis por virus
Hospital Exequiel González Cortés, Santiago, Chile (MZA) Pontificia Universidad Católica de Chile, Santiago Hospital Clínico (MFG).

Clínica Santa María, Santiago, Chile (TBH).

Sociedad Chilena de Infectología.

Comité de Infecciones en Pacientes Inmunocomprometidos (MZA, MFG, TBH)

Recibido: 28 de febrero de 2011 Aceptado: 7 de marzo de 2011

Correspondencia a: Marcela Ferrés Garrido mferres@med.puc.cl 
influenza A H1N1. Sin embargo, en consideración a los factores de riesgo asociados a su enfermedad de base y los tratamientos recibidos, es difícil descartar un papel etiológico contribuyente de los otros agentes infecciosos que fueron identificados aunque estos, cuando afectan el SNC, presentan otro patrón de imágenes en la resonancia magnética (RM).

Evolución: Al tratamiento antimicrobiano se agregó anfotericina B deoxicolato y voriconazol. El aciclovir se suspendió con la recepción del resultado negativo de la RPC para virus herpes simplex 1 y 2. El paciente mostró una leve mejoría pero al sexto día de evolución se agravó debido a una infección por Acinetobacter baumannii, falleciendo a las dos semanas de su ingreso.

El desenlace fatal de este paciente se debió probablemente a los múltiples agentes infecciosos involucrados, consulta tardía, y al uso de corticosteroides en forma empírica en un paciente gravemente inmunocomprometido. Sus condiciones clínicas impidieron realizar una biopsia cerebral la que podría haber contribuido a precisar la etiología del compromiso del sistema nervioso.

\section{Diagnósticos de egreso:}

- Leucemia linfocítica aguda de riesgo medio.

- Encefalitis necrosante aguda asociada a virus influenza A H1N1.

- Bacteriemia por Escherichia coli.

- Neumonía por Staphylococcus aureus meticilina sensible.

- Sepsis por Acinetobacter baumannii.

- Aspergilosis diseminada.

\section{Infecciones del sistema nervioso central} por virus influenza $A$ H1N1 en pacientes inmunocomprometidos

El advenimiento de terapias más efectivas, en base a regímenes de quimioterapia más intensos, ha aumentado la sobrevida de muchos tipos de cáncer, provocando nuevas complicaciones en su evolución; una de las de mayor importancia por su gravedad, es la del SNC ${ }^{1}$.

El caso presentado es el segundo de una serie de niños enfermos de cáncer con complicaciones infecciosas del SNC que publicamos ${ }^{2}$.

El SNC de estos pacientes es susceptible a infecciones por bacterias, virus, parásitos y hongos, las que pueden presentarse como infección única o múltiple y en forma simultánea o seriada. Además, existe una serie de procesos no infecciosos que pueden afectar el SNC y que hacen más difícil aún el diagnóstico ${ }^{1,2}$.

La infección por virus influenza ha sido asociada a variadas complicaciones del SNC (convulsiones, compromiso de conciencia, encefalomielitis aguda diseminada, síndrome de Guillain-Barré, mielitis transversa, etc) las que han sido informadas esporádicamente en la literatura médica en los últimos 60 años, a diferencia de cientos de casos de encefalomielitis necrosante aguda en niños, asociada a la influenza estacional ocurrida en Japón en los años noventa.

Desde el inicio de la pandemia, en el año 2009, se ha informado de numerosos casos con complicaciones neurológicas asociadas a virus influenza A H1N1 en niños; los primeros ocurrieron en Dallas, E.U.A., y luego se han publicado tres series clínicas y un caso publicado en esta revista, en un niño chileno portador de talasemia ${ }^{3}$. Estas complicaciones se presentaron con mayor frecuencia
Figura 1. Resonancia magnética de cerebro en cortes axiales en $\mathrm{T} 1$ que muestra múltiples lesiones cerebrales y cerebelosas hiperintensas, con un área central hipointensa (flechas), compatibles con encefalitis necrosante aguda.
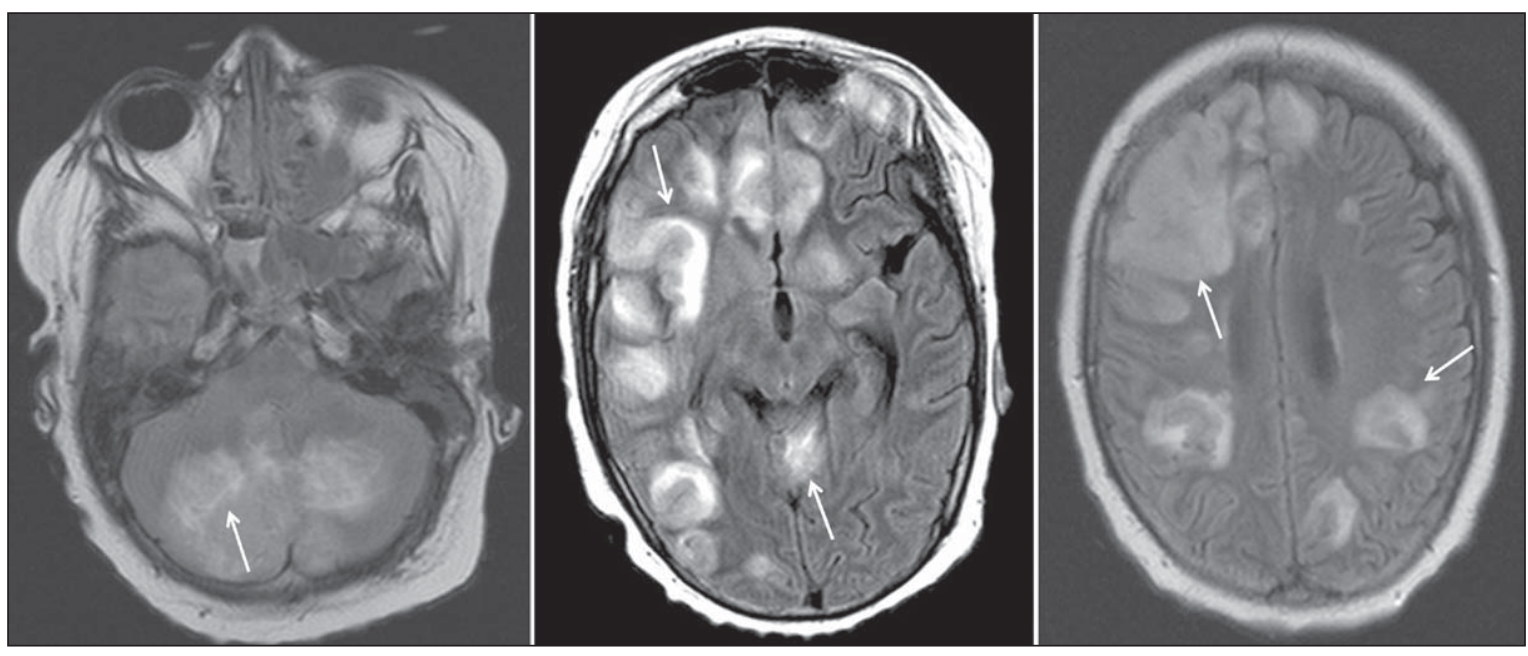
asociadas a virus influenza A H1N14-8. En todos ellos se detectó ARN viral en muestras nasofaríngeas pero no en el LCR.

En inmunocomprometidos, las series publicadas muestran que la influenza se presenta frecuentemente como una enfermedad leve, y que la complicación más habitual es el compromiso pulmonar parenquimatoso en forma de neumonía; todos los pacientes se han recuperado y ninguno presentó complicaciones del $\mathrm{SNC}^{9-12}$.

En nuestro caso, las imágenes son compatibles con una encefalitis necrosante aguda, entidad que ha sido asociada a varios virus y, en especial, a virus influenza ${ }^{4}$.

A pesar de los múltiples agentes infecciosos confirmados en este caso, nos parece como el agente más probable del compromiso del SNC el virus influenza A H1N1, el que fue confirmado por RPC en aspirado nasofaríngeo, pero no en LCR.

La patogenia de esta infección es motivo de controversia. Muy pocos estudios han demostrado partículas virales en el tejido cerebral de autopsias y el aislamiento viral en LCR es muy inusual ${ }^{4}$ lo que hace suponer que se debe más a una respuesta del hospedero que a un efecto directo del virus sobre el SNC.

El tratamiento recomendado es oseltamivir o zanamivir administrados por un período de 5 días $^{13,14}$; estos antivirales han demostrado ser efectivos en acortar la duración de los síntomas y signos de la enfermedad. Algunos expertos recomiendan prolongar el tratamiento en inmunocomprometidos hasta que cese la excreción viral $^{5}$; sin embargo, se han informado casos de resistencia a oseltamivir asociado a esta estrategia ${ }^{10}$.

Según las series publicadas, la influenza ha evolucionado en la mayoría de los casos en forma benigna; no obstante, ha obligado a postergar tratamientos antineoplásicos lo que puede afectar las posibilidades de sobrevida de los pacientes enfermos de cáncer ${ }^{9}$. Esta situación justifica la recomendación de vacunar anualmente a estos pacientes y a las personas que tiene contacto estrecho con ellos. La vacuna trivalente es bien tolerada en pacientes inmunocomprometidos y ha demostrado provocar una respuesta inmune limitada pero aceptable en niños leucémicos, comparada con controles sanos ${ }^{15}$.

\section{Conclusiones}

Este caso nos recuerda la importancia de incluir una RM en la evaluación inicial de los pacientes inmunocomprometidos que cursan con una complicación neurológica, ya que nos puede orientar en forma más precisa que la TAC a sus causas. Los esfuerzos diagnósticos deben ocupar inicialmente métodos no invasores y, si éstos son infructuosos, debe realizarse una biopsia cerebral. En este paciente, la TAC inicial confundió a los médicos clínicos y los métodos diagnósticos usados fueron insuficientes para certificar la etiología del compromiso del SNC en forma precisa. Debido a su condición crítica no se pudo efectuar una biopsia cerebral, la que podría haber confirmado el diagnóstico.

Los médicos debemos estar alerta a esta grave complicación en pacientes que presenten un cuadro gripal acompañado de convulsiones o compromiso de conciencia, especialmente en período de brote epidémico de influenza. Esto con el fin de iniciar un tratamiento precoz, ojalá antes de 48 horas de iniciado los síntomas, de manera de acortar la duración de la enfermedad y reducir sus complicaciones. A la vez, se recomienda vacunar anualmente a los pacientes y sus contactos más cercanos para evitar que esta enfermedad obligue a postergar sus tratamientos oncológicos.

\section{Resumen}

Escolar de 12 años de edad, con Leucemia Linfocítica Aguda en tratamiento que desarrolla una bronconeumonía bilateral, infartos cerebrales compatibles con encefalitis necrosante aguda. El estudio infectológico demostró más de una causas infecciosa que pudiera explicar su evolución destacando influenza A H1N1, Staphylococcus aureus meticilina sensible en lavado bronco alveolar, E. coli y galactomanano en sangre. Se revisa el compromiso del SNC por influenza A H1N1. Se destaca la importancia del uso de resonancia magnética nuclear al evaluar pacientes inmunocomprometidos con complicaciones neurológicas y el aporte de una biopsia cerebral en aclarar la etiología de este compromiso.

\section{Referencias}

1.- $\quad$ Pruitt A. Central nervous system infections in cancer patients. Semin Neurol 2004; 24: 435-52.

2.- Ferrés M, Bidart T, Zubieta M. Importancia de las imágenes y el diagnóstico etiológico en el paciente inmunocomprometido con afección del SNC. Rev Chil Infectol 2010; 27: 541-3.

3.- Bustos B, Andrade F. Encefalopatía aguda y muerte encefálica en un niño con influenza A
(H1N1) 2009 durante la primera ola pandémica. Rev Chil Infectol 2010; 27: 413-16.

4.- Maricich S M, Neul J L, Lotze T E, Cazacu A C, Uyeki T M, Demmler G J, et al. Neurologic complications associated with influenza $\mathrm{A}$ in children during the 2003-2004 influenza season in Houston, Texas. Pediatrics 2004; 114: 626-33.

5.- $\quad$ Ekstrand J J, Herbener A, Rawlings J, Turney B, Ampofo K, Korgenski E K, et al. Heightened neurologic complications in children with pandemic H1N1 influenza. Ann Neurol 2010;
68: 762-6.

6.- Centers for Diseases Control and Prevention. Neurologic complications associated with novel influenza A (H1N1) virus infection in children Dallas Texas. MMWR Morb Mortal Wkly Rep 2009; 58: 773-8.

7.- $\quad$ Webster R, Hazelton B, Suleiman J, Macartney K, Kesson A, Dale R C. Severe encephalopathy with swine origin influenza A H1N1 infection in childhood: case reports. Neurology 2010; 74: 1077-8. 
8.- $\quad$ Lyon J B, Remigio Ch, Milligan T, Deline C. Acute necrotizing encephalopathy in a child with H1N1 influenza infection. Pediatr Radiol 2010; 40: 200-5.

9.- Caselli D, Carraro F, Castagnola E, Ziino O, Frenos S, Milano G M, et al. Morbidity of pandemic H1N1 influenza in children with cancer. Pediatr Blood Cancer 2010; 55l: 226-8.

10.- Launes C, Rives S, Catala A, Berrueco R, Toll T, Camós M, et al. Pandemic influenza A (2009 H1N1) in children with acute lymphoblastic leukaemia. Brit J Haematol 2010;
149: 874-8.

11.- Akyüz S, Yilmaz A, Bülbül M, Erdogan O, Renda R, Demircin G. Do inmunosupressive patients really have an outcome with H1N1 virus infection? J Trop Ped 2011; 57 (2): 129-31.

12.- Redelman-Sidi G, Sepkowitz K A, Huang C K, Park S, Stiles J, Eagan J, et al. 2009 H1N1 influenza infection in cancer patients and hematopoietic stem cell transplant recipients. J Infect 2010; 60: 257-63.

13.- Hartley D, Nelson N, Perencevich E. Antiviral drugs for treatment of patients with pandemic (H1N1) 2009 virus [letter]. Emerg Infect Dis 2009; 15: 1851-2.

14.- Jamieson B, Jair R, Carleton B, Goldman R D. Use of oseltamivir in children. Can Fam Physician 2009; 55: 1199-201.

15.- Shahgholi E, Ehsani M, Salamati P, Maysamie A, Sotoudeh K, Mokthariazad T. Immunogenicity of trivalent influenza vaccine in children with acute lymphoblastic leukemia during maintenance therapy. Pediatr Blood Cancer 2010; 54: 716-20. 